\section{Micromortevida Severina? A comunicação preemptiva dos riscos}

\author{
Micro-death and life of Severina? Preemptive \\ risk communication
}

\section{¿Micromuertevida Severina? La comunicación preventiva de riesgos}

Luis David Castiel 1

Paulo Roberto Vasconcellos-Silva 1,2,3,4

Danielle Ribeiro de Moraes 5

doi: 10.1590/0102-311X00016017

\section{Resumo}

Este ensaio problematiza a abordagem dominante da comunicação dos riscos em saúde. Para isso, acessa e toma para análise conteúdos provenientes tanto de autores que se apresentam como especialistas na área de comunicação de riscos quanto de sequências de mídia audiovisual de amplo acesso. Enquanto parece se configurar uma área de mediação entre expertos e leigos, potencial geradora de inovação tecnológica e de mercadorias passíveis de serem consumidas, a comunicação de riscos em saúde ocupa um lugar biopolítico de reforço da culpabilização dos indivíduos e de propostas individualizantes de evitação dos riscos. O apagamento dos contextos em que ocorrem as exposições ao risco alimenta e é alimentado pela conjuntura neoliberal em que vivemos. Além das tentativas de mediação que são muitas vezes problemáticas, a perspectiva de gestão racional e individual dos riscos, por mais aparelhada por tecnologias inovadoras, não minimiza a precariedade contextual em que ocorre a produção dos riscos sanitários. Paradoxalmente, a crença na gestão dos riscos, presente na abordagem dominante da comunicação dos riscos em saúde, acaba por produzir moralização, ansiedade e mal-estar.

Comunicação; Risco; Saúde

\section{Correspondência}

L. D. Castiel

Departamento de Epidemiologia e Métodos Quantitativos em Saúde, Escola Nacional de Saúde Pública Sergio Arouca, Fundação Oswaldo Cruz.

Rua Leopoldo Bulhões 1480, sala 830, Rio de Janeiro, RJ 21041-210, Brasil.

luis.castiel@ensp.fiocruz.br

1 Escola Nacional de Saúde Pública Sergio Arouca, Fundação Oswaldo Cruz, Rio de Janeiro, Brasil.

2 Coordenação de Pesquisa, Instituto Nacional de Câncer José Alencar Gomes da Silva, Rio de Janeiro, Brasil.

3 Escola de Medicina e Cirurgia, Universidade Federal do Estado do Rio de Janeiro, Rio de Janeiro, Brasil.

4 Instituto Oswaldo Cruz, Fundação Oswaldo Cruz, Rio de Janeiro, Brasil.

5 Escola Politécnica de Saúde Joaquim Venâncio, Fundação Oswaldo Cruz, Rio de Janeiro, Brasil. 


\section{Introdução: em busca de definições de comunicação em saúde}

Atualmente, percebe-se, sobretudo por intermédio do uso de buscadores na Internet, como é prolífica a produção sobre a comunicação do risco na prevenção em saúde. Há muitas definições disponíveis que, grosso modo, não parecem variar de forma importante, até porque há uma matriz instrumental vigorosa hegemônica neste setor. Na verdade, são suas premissas teóricas e categorias de análise que realmente importam. Nesse sentido, como emblemas, vamos apresentar inicialmente o que julgamos serem aspectos que, de alguma forma, parecem representar formas predominantes de definir um âmbito particular de produção de práticas comunicacionais de forte teor pedagógico.

Em geral, são frequentes as ilustrações que mostram diagramas em que há diferentes intersecções de três elementos: avaliação de riscos, gestão de riscos e comunicação de riscos. Em um dicionário virtual do âmbito corporativo, encontramos a seguinte definição operacional: "Troca de informação e opiniões e o estabelecimento de um diálogo efetivo, entre aqueles responsáveis por avaliar, minimizar, e regular riscos e aqueles que podem ser afetados pelos desfechos daqueles riscos" 1.

Como costuma ocorrer nesses contextos em que fica evidente a natureza de mercadoria da comunicação, não se faz qualquer menção ao contexto e fontes de risco, às instâncias geradoras, aos grupos sociais mais expostos, aos recursos econômicos, técnicos e organizacionais para a gestão de tais riscos. O referido contexto diz respeito ao neoliberalismo globalizado. Essa pesada palavra-valise assume sua precariedade ao tentar sintetizar, sem explicar, a grande complexidade de cada um de seus termos, algo que não cabe nesta escrita, mas serve para designar o espírito da nossa época.

Nessa direção, há um visível marketing do produto “comunicação de risco" por várias empresas que vendem correspondentes prestações de serviços e produtos. Dois exemplos encontrados na Internet: Risk Communication Institute (http://www.riskcomm.com/) e o Center for Risk Communication (http://centerforriskcommunication.org/).

No Brasil, vale considerar brevemente como a Agência Nacional de Vigilância Sanitária (Anvisa) apresenta as definições de cunho gerencial em um de seus documentos sobre riscos alimentares, expostos num congresso nacional de laticínios pela área de vigilância de alimentos, em 2002. No conjunto de diapositivos, são mencionados os elementos de análise, gestão/gerenciamento e comunicação de risco, sendo o gerenciamento descrito como o "processo de ponderação das distintas opções normativas à luz dos resultados da avaliação de risco e, se for necessário, da seleção e aplicação das possíveis medidas de controle apropriadas, incluídas as medidas regulamentares” 2 . A definição de comunicação de risco não se afasta muito da primeira definição anteriormente mencionada: "intercâmbio interativo de informações e opiniões sobre os riscos, entre as pessoas encarregadas da avaliação dos riscos e do gerenciamento dos riscos, os consumidores e outras partes interessadas" 2.

As manifestações de terrorismo exacerbado são parte essencial do espírito belicoso da nossa época e têm como marco de referência o evento sintomático da queda das Torres Gêmeas em Nova York (Estados Unidos) no início deste milênio. Inevitavelmente, uma temática como a da comunicação do risco não pode se abster de se presentificar diante de situações dessa ordem. Um documento elaborado pelo Consórcio Nacional para o Estudo do Terrorismo e Respostas ao Terrorismo, denominado Compreendendo a Teoria da Comunicação do Risco: Um Guia para Gestores de Emergência e Comunicadores traz a questão de se definir comunicação de risco ${ }^{3}$.

Para isso, afirma que as definições são frequentemente similares a uma noção de 1992 de Covello 4 . $\mathrm{Na}$ essência, tão-somente consistiria no "processo de troca de informações entre partes interessadas sobre a natureza, significância ou controle do risco" 3 . Nesse sentido, a ideia de efetividade desse processo inicialmente abordou a criação da mensagem e se desenvolveu tendo em vista as questões relativas a como os receptores processavam e atuavam diante das mensagens. Entre outros, é citado o trabalho seminal de B. Fischhoff 5, que postulou, como outros pesquisadores do campo, que se deve levar em conta como os vários públicos percebem o risco influenciados por fatores sociais e culturais, mais do que apenas se baseando em ciência. 


\section{A comunicação do risco em saúde pública}

As perspectivas anteriormente mencionadas não destoam, essencialmente, da perspectiva do enfoque acadêmico do risco em saúde pública. Não se pode desconsiderar como um representante fidedigno desse campo, as proposições pertinentes à nossa discussão, o livro de Bennett et al. 6 ao colocarem as questões da temática no âmbito britânico, no seu compêndio sobre comunicação do risco e saúde pública. A posição diante dos riscos em saúde pública leva em conta a necessidade de dirigir-se a um considerável número de pessoas, se não exatamente à população em geral, decerto a indivíduos especialmente vulneráveis a determinados riscos.

Nesse sentido, o título da primeira seção do livro é sintomático: Risco, Comunicação e o Entendimento Público da Incerteza em Saúde Pública. Na introdução, intitulada: Compreendendo as Respostas Públicas ao Risco, assume-se que deve-se considerar que as reações sociais diante dos enunciados de riscos podem parecer desarrazoadas, quando cotejadas com os mandatos das evidências científicas. Em geral, o risco em saúde costuma ser encarado como sendo a "probabilidade do evento ocorrer vezes a gravidade do dano, diante da exposição a supostos riscos" 6 (p. 7). Mas, a apresentação de dados relativos a riscos em casos específicos nesse sentido pode tanto provocar reações de alta ansiedade como de quase indiferença. Tais modos de se comportar não são obrigatoriamente irracionais.

Os autores se colocam diante dos desafios da comunicação do risco procurando a discussão do contexto: "...A codificação da informação, a maneira como é transmitida e os processos para decodificá-la são centrais em todas as formas de comunicação (...). Muitos problemas de comunicação ocorrem porque elementos deste processo são rompidos. Em algumas instâncias, a comunicação pública e individual ficam operacionalmente misturadas..." 6 (p. 6).

Mesmo não se dirigindo diretamente a situações sociais relacionadas a grupos precarizados no interior de contextos conflitivos, vale a pena acompanhar seus argumentos: "(a)s controvérsias sobre os riscos em saúde raramente provêm apenas de questões de comunicação, mas de comunicação precária, que muitas vezes um fator em permitir que as disputas se agravem e grupos discordantes se tornem polarizados (...). De um ponto de vista, 'o público' - estimulado pela mídia - pode ser acusado de ignorar recomendações perfeitamente sensatas e cientificamente sólidas. Por outro lado, aqueles responsáveis pelas recomendações podem ser vistos como não confiáveis, dissimulados, ou inclinados a posturas paternalistas" 6 (p. 3).

Nas últimas quatro décadas, os resultados de estudos sobre as reações públicas diante das recomendações quanto aos riscos à saúde trouxeram novos elementos relevantes a respeito desta questão. Há um progressivo afastamento da valorização das percepções consideradas erradas, devido à suposta ignorância ou desleixo das pessoas, para uma perspectiva na qual se encara a comunicação de riscos como um processo de interação recíproca entre aqueles que são considerados leigos e os especialistas. Deve-se considerar o contexto no qual se dá essas relações, inclusive colocando-se em discussão a natureza da evidência científica em si como fonte insofismável da verdade.

Coloca-se a necessidade de se começar a considerar outras formas menos culpabilizantes de tratar muitas das reações defensivas quanto ao risco pelas autoridades governamentais e pelos responsáveis por políticas públicas em prevenção/promoção de saúde. Decerto, permanecem percepções públicas mal informadas sobre questões de prevenção em saúde: as pessoas podem ter medo dos perigos errados e não tomar cuidados (caso estejam a seus alcances) diante de exposições a riscos indiscutíveis. Mas, importa criar discussões para se obter um ambiente mais favorável para debates sobre riscos para além de recomendações autoritárias que somente apelem para mandatos moralistas de autodisciplina/autocontrole.

Ainda assim, processos de comunicação do risco supostamente mais efetivos podem não resolver, talvez, nem mesmo amenizar dilemas e paradoxos relativos a situações de perigos e incertezas. Nem trazer maior compreensão ou fazer com que as pessoas obrigatoriamente adotem comportamentos seguindo ideários da vida saudável. Em suma, achados de pesquisas empiricistas no contexto das democracias liberais, entre outros aspectos, consideram que riscos e valores das pessoas são diferentes, probabilidades podem ser difíceis de interpretar e debates sobre risco são condicionados por seu contexto social/político 6 .

Nesse sentido, os autores expõem que os riscos são geralmente mais preocupantes (e menos aceitáveis) se percebidos: (a) como sendo involuntários (ex.: exposição à poluição) mais do que voluntários (esportes radicais); (b) quando desigualmente distribuídos (alguns se beneficiam e outros sofrem as 
consequências); (c) quando inescapáveis, mesmo tomando precauções pessoais; (d) surgindo de fonte nova, não conhecida; e) resultando de fontes feitas pelo homem, mais do que de fontes naturais; (f) causando danos latentes ou irreversíveis (ex.: o surgimento de doença muitos anos após a exposição); (g) colocando algum perigo em particular para crianças pequenas e mulheres grávidas, ou ainda, mais genericamente, para as futuras gerações; (h) trazendo a ameaça sob a forma de morte (ou doença/ dano) que provoque terrores/medos particulares; (i) atingindo vítimas identificáveis mais do que anônimas; (j) sendo precariamente entendidos pela ciência; $(\mathrm{k})$ como sujeitos a afirmações contraditórias de fontes responsáveis (ou, pior ainda, da mesma fonte) 6.

Ainda para Bennett et al. 6, pessoas são diferentes: (a) respostas ao risco são também dependentes aos valores pessoais, crenças políticas e morais, atitudes em relação à tecnologia etc.; (b) reações individuais ao risco podem depender mais fortemente da aprovação ou desaprovação da fonte de risco em outros aspectos, ou seja, na relação riscos/benefícios, estes últimos importam (e incluem a dimensão de prazer envolvida e a relação específica de indivíduos com elas).

A primazia dos valores individuais foi destacada no contexto da relação médico/paciente. Diferentes pacientes confrontados com as "mesmas" escolhas podem considerar riscos relevantes e benefícios de maneiras bem diferentes de outros. Indivíduos também variam em suas crenças sobre a responsabilidade pela escolha.

No campo da saúde pública também existe a questão de haver muitos porta-vozes da promoção em saúde dirigindo mensagens preemptivas (esquematicamente, sob a forma de ataques hiperpreventivos, antes mesmo de se perceberem indícios de perigo) a muitas pessoas ao mesmo tempo. Assim, todos esses indivíduos, expostos ou não, passam a ser responsáveis por alterar comportamentos não saudáveis, mesmo sendo mantido tanto o seu direito de decisão como a liberdade de escolha no mercado a produtos e/ou práticas vistas como danosas à saúde. Mas se em sua dimensão de (suposta) autonomia receber necessárias e suficientes informações, nada mais lógico do que se afastar racionalmente das coisas que fazem mal à saúde. Só que, como assinalam Bennett et al. 6, já se começa a assumir no contexto sanitário britânico que o comportamento leigo não é tão-somente reativo e desarrazoado como já foi considerado. Ainda mais, tendo em conta que a segmentação dos diferentes públicos potenciais é um tema do marketing social. Começa com a proposição de que aqueles que querem influenciar o comportamento em nome de uma ideia utilitarista do bem público precisam conhecer suas múltiplas audiências, assim como empresas comerciais. Esse uso levanta questões éticas quanto às possibilidades de se usar métodos manipulativos em nome de uma causa supostamente correta.

Inevitavelmente, a comunicação do risco envolve questões de gestão e de políticas públicas: quanto às formas como se gera e se sustenta a confiança (qual é a fonte da informação mais que o teor das mensagens); os processos sobre a amplificação dos interesses (mercado) sobre formas específicas de perigo e o papel da mídia em ambos os processos. Os desafios em lidar com a percepção e a comunicação do risco são elevados pela natureza múltipla dos processos de comunicação e a dificuldade de se obter verificação quanto ao retorno das mensagens disseminadas a audiências amplas. Mas não só.

No Brasil, a comunicação como âmbito de emissão de informações e práticas sociais tem uma história de interações com a esfera da saúde desde o começo do século XX. Isso aconteceu de forma vinculada às políticas de saúde e às regulações de controle sanitário, nas circunstâncias das relações recíprocas de implantação do modelo sanitarista de assistência à saúde 7 . A comunicação do risco foi instituída no Brasil pretendendo aquilatar e gerir riscos ligados aos desenvolvimentos científicos e tecnológicos, sobretudo aqueles referentes a sistemas industriais complexos, como os de química fina e de energia atômica.

Nos anos 1980, a análise de riscos também se tornava uma forma de lidar predominantemente com as articulações políticas com vistas, primordialmente, à produção de consensos nas esferas de decisão. As resoluções de cunho técnico que deveriam atender necessidades coletivas se reduziam a argumentos retóricos para camuflar a despolitização das discussões quanto à aceitabilidade dos riscos, ao justificar decisões políticas e econômicas em termos de ações estrita e supostamente técnicas 8 .

Atualmente, em termos breves, seguindo Rangel 7, nos deparamos com três questões cruciais:

- As relações entre o Estado e corporações privadas e grupos precarizados submetidos a múltiplos riscos, tendo em vista os déficits de confiabilidade institucional nas operações regulatórias das situações de risco social; 
- As formas como a mídia concebe e elabora retoricamente as notícias que envolvem contingências de risco, eventualmente incidindo em exageros inconvenientes capazes de gerar alarmes desnecessários. E, também, sustentando a supremacia descontextualizadora de uma perspectiva empírico/lógica de ciência. Ademais, pode-se ter a omissão de possibilidades alternativas de análise das circunstâncias, evitando-se atritos provenientes de diferentes pontos de vista éticos e científicos que sobrevêm nas interações com os recipientes das informações e com as autoridades expertas. Em síntese, emissores vinculados a grandes empresas de comunicação descrevem fatos, emitem juízos morais e formulam interpretações relativas a situações de risco, conforme interesses que podem não servir aos destinos de grandes grupos sociais precarizados;

- Há vicissitudes em que a comunicação é passível de intensificar riscos e incentivar a demanda por mercadorias, serviços e práticas de alterações comportamentais (ditas mudanças de estilo de vida que as pessoas escolheriam de modo desavisado) em nome da hiperprevenção da saúde, em conformidade com os interesses mercadológicos das empresas e corporações que comercializam tais produtos 7 .

\section{Os riscos da comunicação do risco: micromorte e microvida Severinas}

Antes de continuar, um pedido de escusas a João Cabral de Melo Neto pela apropriação do título de sua obra-prima. Mediante um jogo de palavras que, correndo o risco de engano, tem a suma pretensão de estar adequado ao fluxo argumentativo deste ensaio, também com boa dose de crítica, mas sem o lirismo de um grande poema.

Se, como vimos, a comunicação do risco tem seus riscos, pesquisadores e experts na temática podem não tomar os devidos cuidados com a complexidade das questões contextuais e estruturais que envolvem os campos das relações entre risco, ciência, saúde e sociedade. Esse é o propósito desta seção: ressaltar como emblema em negativo a enfoques biopolíticos conservadores que produzem uma perspectiva ontológica do risco, mediante discursos supostamente pedagógicos baseados em um cientificismo probabilístico biologicista.

É massiva a difusão na Internet de estratégias institucionalizadas dessa índole, alegadamente pretendendo promover uma compreensão pública do risco, com ênfase na prevenção preemptiva em saúde, como já mencionado. Condizente com os fluxos globais de bens e mercadorias que sabidamente participam ativamente da geração de grandes desigualdades socioeconômicas.

Uma dessas abordagens comunicacionais é realizada pela série Risk Bites (http://riskbites.org, acessado em 27/Jan/2017) com cartuns animados quadro a quadro, realizados pelo pesquisador desenhista Professor Andrew Maynard, da Escola para o Futuro da Inovação na Sociedade da Universidade do Arizona, Estados Unidos. É um especialista em nanotecnologia e possui um site/blog chamado 2020 Science (http://2020science.org, acessado em 27/Jan/2017), que se dedica a difundir informações com base em perspectiva proporcionada por esta mesma expressão (2020 Science). Essa abordagem é um ambicioso programa de alta tecnologia, voltado a formar uma futura geração de cientistas computacionais e construtores de ferramentas informáticas, capacitados a utilizar novas abordagens instrumentais para lidar com questões fundamentais das ciências da natureza. A ênfase se localiza na modelagem computacional de sistemas naturais, se estendendo da biologia à medicina, desde aspectos extracelulares no nível molecular até os contextos dos sistemas antropogênico e terrestre em escala global (não fica claro se a escala global faz referência à dimensão global do capitalismo ou tão-somente planetária. Ou, quiçá, a ambas).

No site de Maynard aparece uma chamada coloquial para a sua série de cartuns animados: "Alguma vez você se perguntou o quanto os cigarros eletrônicos são saudáveis, se as vacinas são uma boa idéia, ou o quão tóxico pode ser o sangue de um alien? Descubra mais sobre a ciência do risco em Risk Bites". Ou seja, há um indisfarçável apelo popular para captar o interesse leigo daqueles que estejam buscando informações sobre tal temática.

Aparentemente, o título da série de vídeos parece fazer um jogo de palavras em inglês com o substantivo no plural bites (baseando-se na conhecida palavra/valise bit - binary digit) como unidade de medida da dimensão de arquivos informatizados. Explicitamente, a referência ao verbo "to bite" morder - é evidente. Isso aparece em um dos primeiros episódios (A Ciência do Risco: Uma Introdução ao Risk Bites). Logo no início, é indicada a situação de se começar a comer uma rosquinha (doughnut) 
que cai no solo. É feita uma menção irreverente a uma suposta lei popular de que três segundos para o risco de "contaminação" de algum alimento sólido que vai ao chão e a possibilidade de comê-lo ser uma prática segura. O tom das animações é ameno e pretende apresentar com clareza didática as questões sobre risco - na verdade, bem mais intrincadas para além dos enfoques empírico-lógicos e das dimensões objetivantes técnico-estatísticas que a série pretende elucidar.

Da mesma forma, em 2007, David John Spiegelhalter, um renomado estatístico britânico, foi escolhido Winton Professor of the Public Understanding of Risk do Laboratório Estatístico da Universidade de Cambridge. Spiegelhalter é um pesquisador altamente citado no Institute for Scientific Information (ISI) e possui um site pessoal (http://www.statslab.cam.ac.uk/Dept/People/Spiegelhalter/davids.html) e um blog denominado Compreendendo a Incerteza (http://understandinguncertainty.org/). Nesse portal há uma matéria representativa de sua proposta - servir de árbitro/referência autorizada diante de afirmações sobre o risco - seja pela mídia leiga ou mesmo pela academia.

Por exemplo, discute-se a afirmação do presidente Barack Obama em janeiro de 2015, que na visita de três dias a Delhi, na Índia - um ambiente com altos níveis de poluição aérea - o teria feito perder seis horas de vida. Diante dessa declaração, Spiegelhalter, sem modéstia, explicita que foi ele mesmo quem elaborou essa estimativa com base em evidências de (apenas) um artigo de 2009 do New England Journal of Medicine 9 . Brevemente, mesmo admitindo as possíveis fragilidades quanto às pertinências desse estudo, poderemos assinalar: (a) a perspectiva usualmente descontextualizadora de outras dimensões socioculturais das pessoas, da época e do lugar nessa linha desses estudos epidemiológicos, (b) no interior da lógica de produção de solidez das evidências, nem mesmo se refere a revisões sistemáticas. E, ainda, talvez não seria absurdo indagar se não poderia haver nas entrelinhas algum indício de juízo colonialista, diante das precariedades indianas (mesmo o país sendo considerado membro do bricabraque econômico, assim designado pelo acrônimo BRICS).

Ademais, Spiegelhalter aparece em vídeos de palestras e curtas metragens com narrativas sobre a gestão dos riscos à saúde. Numa delas, sendo designado como "Professor Risk", mostra o início do dia de um Spiegelhalter e seu duplo antípoda ao se levantarem juntos da mesma cama: um que se expõe - sintomaticamente reproduzindo o consagrado código de cores semafórico - usa camiseta vermelha - e o outro - logicamente de verde - se previne. Os riscos já começam no café de manhã, ao se decidir se a refeição é arriscada - ovos com bacon - ou saudável - um mingau inglês (porridge). O meio de transporte para ir ao trabalho inclui, respectivamente, conduzir com atenção um carro ou dirigir de modo descuidado uma bicicleta pelas ruas de Cambridge, e assim por diante. Perto do desfecho, algo, de certa forma surpreendente, ocorre: Spiegelhalter, envergando uma camiseta parte verde, parte vermelha, toma bebida alcoólica e toca surdo num ensaio de escola de samba em um clube da cidade...

A mensagem: é impossível viver sem exposições aos riscos, desde que se saiba equilibrar consciente e saudavelmente as medidas de exposições a prazeres, mas com a devida moderação, pois se está vetado moralmente a se entregar incontrolavelmente à desbragada dissolução - uma boa metáfora sobre perder a organização sólida/degenerar em meio ao efeito de líquidos inebriantes.

Claro, o enfoque é dirigido, como costuma acontecer, à responsabilização pessoal na gestão securitária dos riscos. O final, sem dúvida, é feliz, o Spiegelhalter cuidadoso e seu duplo desregrado, ambos de pijama, sem as camisetas que os diferenciavam, voltam apaziguados ao leito de onde saíram e, harmoniosamente, fundem-se, desfazendo-se a ambivalente duplicidade, rumo a um sono unificado e reparador - importante para a saúde.

Não cabe aqui recensear a obra de Spiegelhalter, mas importa indicar seu papel na divulgação de um ideia objetivante e, ao mesmo tempo, sustentadora da noção do risco como matriz agenciadora de estratégias biopolíticas (ou epidemiopolíticas) de gestão utilitarista e de produção de subjetividades. Spiegelhalter sustenta a viabilidade de educar as pessoas para compreender a ideia de risco como forma racional para gerenciar seus cotidianos em um contexto neoliberal. Há vídeos educativos como $O$ Prazer da Estatística, cuja continuação é Coroa, Você Ganha (como resultado do sorteio no jogo da moeda ao ar), do qual foi produzido um excerto intitulado Maximize suas Chances de Viver Até os 100 Anos.

Em seu livro em coautoria com David Blastland: As Crônicas da Norma, Histórias e Números sobre o Perigo 10, são criados personagens fictícios para mostrar riscos e perigos à saúde. Em síntese, o livro começa com um pequeno conto sobre o perigo terrorista - um tema fundamental no contexto das economias neoliberais avançadas onde três pessoas Norm, Prudence e Kevin têm diferentes reações diante de mochilas e sacolas deixadas nos seus trajetos no metrô londrino. Além disso, relata os dados 
sobre as bombas em mochilas que explodiram no metrô em julho de 2005 e as estatísticas de 30 mil bolsas e mochilas esquecidas em 2011 no metrô. Logo depois, a história verídica de uma esquiadora que cai no interior de um riacho de água parcialmente congelada, consegue ficar respirando em uma bolha de ar abaixo d'água, mas sofre de hipotermia por um tempo prolongado, tem uma parada cardiorrespiratória, mas consegue ser salva, ficando paralisada do pescoço para baixo, mas acaba se recuperando a ponto de voltar a suas atividades profissionais.

Os autores fazem uma distinção entre probabilidades dos experts (os números) e as dimensões subjetivas do risco (em relatos particulares) das pessoas em suas vidas singulares, mas a impressão que fica é que não se pode abrir mão da importância de se compreender as estatísticas para orientar a ação preventiva das pessoas em suas narrativas de vida.

"Os números e probabilidades (...) mostram as chances de uma variedade de sortilégios e trapaças da vida (...). Dizemos como conhecemos certos riscos, porque não podemos conhecê-los e como eles mudaram, e usamos os melhores métodos que encontramos ou inventamos para que possamos captá-los com facilidade. Em particular, usamos um engenhoso recurso chamado micromorte e um novo, chamado microvida..." 10 (p. 5).

Essa mesma proposta aparece em sua proposição da metáfora da velocidade de uma corrida como equivalente da distância em relação ao tempo de vida em termos de riscos absolutos associados a supostas exposições a fatores responsáveis por doenças crônicas ${ }^{11}$. A microvida, diferentemente da micromorte que trata das probabilidades em termos de riscos absolutos de morrer, trata das possíveis perdas em termos de tempo cronológico referentes à exposição a fatores de risco relacionados a doenças crônicas.

Spiegelhalter admite algumas limitações na ideia de microvida: (1) por se tratarem de médias relativas a populações e períodos, não levam em conta a variabilidade entre as pessoas em suas exposições a benefícios ou danos e não se aplicam a idades específicas ou exposição única; (2) baseiam-se na diferença epidemiológica entre grupos de pessoas e não necessariamente à consequência etiológica do respectivo comportamento em indivíduos, nem de sua correspondente alteração em indivíduos; (3) as estimativas são grosseiras, devido à variabilidade amostral, sobretudo pelas inevitáveis limitações dos estudos epidemiológicos ao tentar quantificar o efeito associado com um fator único isoladamente. Algo que é criticável em função do confundimento; (4) efeitos podem ser enquadrados como microvidas perdidas por exposição a ações de risco ou ganhos pela respectiva evitação. A escolha de uma linha de base de 35 anos é optativa, permitindo avaliar com pertinência variações de dez anos para mais e para menos; (5) não se leva em conta a qualidade de vida ao se adicionar anos à sobrevida; (6) a ideia de microvida pode ensejar a equivalência de uma proteção por um risco, por exemplo, exercício físico para não fazer dieta, algo que nem sempre seria despropositado, segundo estudos.

Mesmo assim, Spiegelhalter considera pedagógica a metáfora da "microvida", pois pode ser facilmente transmitida em função da ideia de velocidade com a qual as pessoas vivem seu tempo de vida, indicado pela da expectativa média de vida. Essa posição fica mais clara ao Spiegelhalter se dirigir à comunidade acadêmica para propor formas "mais analíticas", leia-se racionais e utilitárias, de se visualizar a "incerteza no futuro", sintomaticamente exemplificando com decisões relativas ao âmbito das finanças:

"Diante da incerteza sobre o futuro, as pessoas confiam bastante em suas intuições para tomar decisões (experiências, afeto e emoção), opiniões de conhecidos e crenças culturais. Por milênios, estas respostas intuitivas nos serviram bem, mas há situações em que uma abordagem analítica provavelmente vai oferecer maior precisão e um discernimento mais profundo. Por exemplo, um indivíduo pode estar diante de uma decisão financeira. Em uma abordagem mais analítica, uma sensação geral de incerteza sobre o futuro é substituída por dois componentes: uma lista de possiveis desfechos e uma avaliação de suas probabilidades. Tais avaliações podem ser feitas tendo como base julgamentos ou pressupostos sustentados por modelos estatísticos, que inevitavelmente introduz um elemento subjetivo. Alguns argumentam que 'probabilidade não existe'; nosso ponto de vista é que as probabilidades são melhor tratadas como vantagem razoável de aposta [reasonable betting odds] construída a partir do conhecimento disponivel e da informação" 12 (p. 1393).

Enfim, nos deparamos com as noções de micromorte (micromort) e microvida (microlife) também apresentadas por Maynard no vídeo Risk Bites e Riscos de Morte - Tempo para Obter uma Microvida. Micromorte seria um expediente que ajusta usando-se a multiplicação por 1 milhão de uma taxa de mortalidade por uma determinada causa. De modo que se pode traduzir pequenos riscos de morrer em números inteiros que permitiriam comparação mais fácil (ex: o risco de morte por 
anestesia é referenciado como sendo de 1 em 100 mil. Isso corresponderia a 10 micromortes por cirurgia). Microvida seria meia hora da expectativa de vida de um adulto, que é aproximadamente equivalente a um em um milhão de vida após os 35 anos.

Ora, já se conhece esse tipo de estimativa há um bom tempo: uma microvida seria "desperdiçada" ao se fumar dois cigarros ou estar cinco quilos acima do peso, tomar o segundo e terceiro drinks alcoólicos ao dia, assistir a duas horas de televisão ou comer um hambúrguer. Por outro lado, microvidas podem ser obtidas comendo-se frutas e vegetais, fazendo exercícios e tomando estatinas 11.

A noção de micromorte foi concebida por Ronald Howard em 1989, como uma forma didática ao alcance dos pacientes para explicar riscos de condições médicas ou tratamentos para considerarem tais riscos ao tomarem decisões médicas 13. Para isso, é proposta uma mudança de escala para a descrição de riscos de morte por meio de uma unidade que apresente números inteiros usando-se a microprobabilidade de um em um milhão. Uma micromorte equivale a uma microprobabilidade de morte.

Assim, as narrativas existenciais de cada um deveriam incorporar elementos que buscariam dar sentido à experiência do individualismo em um contexto neoliberal globalizado totalitário, que torna o cuidado de si como uma responsabilidade pessoal que obriga a se praticar rituais obsedantes de autoesquadrinhamento.

Veja-se, por exemplo, este trecho de Spiegelhalter:

"Portanto, a penalidade por ser-se do sexo masculino equivale a fumar oito cigarros ao dia, morar na Rússia ao invés de na Suécia equivale a quarenta cigarros ao dia para homens e vinte para mulheres, enquanto viver em 1910 ou 1980 em oposição à atualidade equivale respectivamente a trinta ou dez cigarros ao dia, respectivamente" 11 (p. 2, grifos nossos).

Como é possível dar algum sentido razoável a tais comparações bastante discutíveis, cujas premissas podem refletir estratégias aversivas ao risco, sem explicitar as atribuições de valores moralistas ao usar o tabagismo como "padrão-vilão"? Mesmo com todas as ressalvas da solidez de sua proposta, Spiegelhalter não deixa de fazer afirmações discutíveis. Refere-se à "penalidade” por se pertencer ao sexo masculino (quem sabe possivelmente devido à existência de um cromossomo Y ao invés do $\mathrm{X}$ ), sem avaliar as dimensões socioeconômicas e culturais; compara dois países sem considerar suas matrizes sociais, culturais e geopolíticas; e coteja períodos históricos sem trazer suas especificidades. E, ao mesmo tempo, estabelece um tendencioso gradiente de salutarismo, em função da suposta vida mais saudável contemporânea, possivelmente baseado em dados demográficos de expectativa de vida. Deixa de mencionar os profundos diferenciais dessa distribuição demográfica planetária no que se refere, em linhas bem esquemáticas, aos processos de acumulação de capital viabilizados pelos processos coloniais ao longo do período em foco.

\section{Gestão dos riscos dos riscos?}

O programa do canal de TV a cabo brasileiro GNT, chamado Até Quando Você Quer Viver, é comandado pela figura resoluta e imponente da Dra. Márcia Franckevicius. Ela ocupa o lugar de autoridade médica em promoção e prevenção de saúde. Esse é apenas um dos muitos assim chamados reality shows que exploram esse veio temático.

Vamos tomar um dos episódios que costumam seguir a mesma fórmula: a tentativa de conversão aos rituais quase religiosos do estilo de vida saudável por parte de indivíduos que não conseguem adotar os preceitos corretos em relação às práticas hiperpreventivas de saúde. Portanto, correm riscos que podem abreviar suas vidas, segundo os conhecimentos médico-epidemiológicos apresentados de maneira peremptória pela Dra. Márcia.

Trazemos o episódio Ismael 14, caso de um representante comercial aparentemente da indústria farmacêutica, 32 anos, que "simplesmente não tem regras", segundo a locutora do vídeo. O protagonista é uma pessoa com peso acima do recomendável, com excessiva gordura abdominal, que se alimenta mal devido às contingências de seu trabalho, asmático, tabagista (trinta cigarros ao dia), divorciado. Diz a médica que a má postura de Ismael "pode ser sinal de uma vida muito estressante".

Começa o seu tratamento levando-o para praticar natação na piscina de uma academia. Pergunta se ele está pronto para mudar de vida. Diante da resposta positiva afirmando sumariamente que ele deve nadar para melhorar sua capacidade respiratória, pois fuma e tem asma, diz que ele deve começar 
a nadar de manhã cedo, antes de ir para o trabalho. Depois de breves orientações de um instrutor, Ismael começa a nadar, desajeitadamente. Facilmente se percebe que ele nem nada bem, nem tem disposição física para realizar este esforço. Logo admite que "foi bem complicado". Depois disso, ele recebe também recomendações dietéticas ${ }^{14}$. Em suma, baseando-se em uma perspectiva crítica, não é difícil presumir as dificuldades por que passará Ismael para, de fato, mudar sua forma de vida de maneira sustentada, desde que não caiamos num enfoque de culpabilizar a vítima.

Depois de tratar da produção de estratégias de comunicação de uma perspectiva materializada do risco no interior de uma ideia de gestão social do medo, é possível começar a criticar a sua constituição como verdade e as implicações deste giro. Aproveitamos uma conhecida noção de Cornelius Castoriadis, a "escalada da insignificância", no sentido de conformismo generalizado diante da carência na atribuição de significados satisfatórios na época moderna 15. Aplicamos essa noção aos acontecimentos acelerados no interior da cultura tecnológica capitalista neoliberal, que erige como forma simbólica o conceito de risco e o utiliza para veicular formas de prover segurança aos indivíduos, que devem seguir responsavelmente preceitos baseados em categorias e conceitos que não são discutidos, e adotar (consumir) medidas restritivas em nome da vida saudável. O prêmio é uma promessa de longevidade com vitalidade, mas esta promessa, assim como "é" o risco, constitui uma probabilidade em aberto. Não há forma de se garantir que vá se concretizar. Não deixa de ser uma aposta, ou um contrato de risco. E por mais tempo que se viva, a finitude, apesar das visões imortalistas, permanece como desfecho.

Essa configuração, ainda que esquemática, pode ser um elemento para se tentar entender, usandose alegoricamente o jargão econômico, porque essa conta não fecha. Há que se lidar com o risco como algo vinculado à ansiedade e/ou com o mal-estar e/ou medo nesta nossa civilização, cujo cotidiano para um enorme contingente de pessoas é bastante precário em muitos aspectos.

Curiosamente, a palavra precário, além de significar pouco, insuficiente, escasso, tem uma acepção com ampla afinidade com o risco: "que tem pouca ou nenhuma estabilidade; incerto, contingente, inconsistente" 16. Ademais, é interessante conhecer a etimologia: precarius, do latim precarius, significa "obtido por meio de prece; tomado como empréstimo; alheio, estranho; passageiro" 16 . Consultando o verbete em inglês, encontramos algo mais: "dependente da vontade ou do favor de outro" 17.

Isso é o suficiente para introduzir a ampla noção de precariado, criada pelo economista Guy Standing, que pretende substituir as categorias de "classe média" e "proletariado" ao incluir vários grupos sociais heterogêneos que são caracterizados por sofrerem de insuficiências em termos laborais (e de identidade baseada no trabalho), econômicos, sociais, securitários, de formas de lazer, de moradia etc. 18. Houve, como de costume, críticas ao livro, que o autor procurou responder na segunda edição da obra e em outro livro, mas isto não vem ao caso agora. Segundo Bauman \& Donskis 19, o que vincula (paradoxalmente) esse grupo é a sua profunda desintegração, incerteza social, solidão e humilhação.

Ademais, são passíveis de sofrer de raiva, anomia, alienação e ansiedade 18. Vamos, aqui, nos deter na dimensão da ansiedade para além dos critérios classificatórios do Diagnostic Statistic Manual. É preciso propor que uma das formas de expressar o mal-estar nosso de cada dia nesta civilização seria na linguagem do risco. Ou, de outro modo, por intermédio dos discursos sobre os riscos que lidamos em nossas existências, tendo novas dimensões de insegurança cujo efeito é que quanto mais nos reconhecemos sob risco, mais somos afetados por algo que pode ser chamado de ansiedade, ou mesmo, de sofrimento difuso ou, simplesmente, medo.

Algumas vertentes das chamadas "Humanidades" estudam as perspectivas "materializadas" entre as percepções sociais do risco e a experiência de sofrimento. Isso serve para cumprir a função crítica sem a obrigatoriedade de assumir instrumentalmente a "propositividade" de cunho conservador, pois só se admitem mudanças de trajetórias desde que a meta da acumulação/crescimento econômico seja mantida. Em síntese, a sustentabilidade do neoliberalismo é axiomática. Mas é preciso poder mostrar as conexões entre a racionalidade neoliberal e a suspeita de haver algo muito equivocado na qualidade de nossa vida cotidiana e nas relações com os nossos, assim designados, semelhantes.

Para Wilkinson 20, os relatos culturais da nossa época a tratam como estando excessivamente apreensiva diante da perspectiva intimidante de incertezas ameaçadoras à integridade de cada um de nós. Desse modo, a procura constante de controle antecipatório dos riscos e gestão do medo está relacionada à necessidade securitária de proteção diante dos perigos obstinadamente reiterados por vários meios de canais de comunicação dos riscos, sejam sistemas leigos ou peritos. 
Sem maiores aprofundamentos, incompatíveis com a extensão de um artigo, podemos descrever este período histórico como sendo reflexo dos presentes modos de arranjo social, econômico e cultural. Tal configuração produz formas de organização social em que a ideia própria de individualidade deve dar conta de atribuladas relações laborais altamente competitivas e, eventualmente, precarizantes. E, também, das grandes pressões consumistas. Somos envolvidos por processos geradores de formas de vida delineadas por elementos contingenciais históricos, sociais e econômicos que participam ativamente de nossa subjetividade.

Especialmente dos anos 1980 em diante, combinam-se duas dinâmicas de individuação. Há intensas demandas institucionais sobre as pessoas em termos de responsabilização individual por meio das pressões modeladoras de subjetividades que emanam da conjuntura social. Ao mesmo tempo, as pessoas que não estão em situação de precariedade se colocam diante das instituições demandando mais liberdade pessoal frente à ênfase do lugar do indivíduo nas sociedades modernas 21 .

Produzem-se situações paradoxais. Por um lado, ocorre a fragilização dos sistemas sociais de proteção, a individuação gera imobilização das pessoas destituídas dos recursos necessários para a ação, enquanto são convocadas cinicamente à superação com o empenho e a dedicação sobre si próprias. Aqui, pode-se deparar com formas de institucionalização do "precariado", para onde os mais fracos são compelidos a aceitar qualquer forma aviltante de atividade econômica, legitimando a precariedade de suas existências.

Por outro lado, a individuação muitas vezes captura as pessoas em práticas de controle social. Também, os processos ensejam vigoroso domínio tecnológico instrumental do mundo material e uma ênfase na autodisciplina para determinar as fórmulas e trajetórias para se atingir destinos apresentados como desejáveis. Prioritariamente, deve-se buscar a sobrevida mais longeva que os objetos técnicos possam proporcionar. Ao mesmo tempo, muitos estão mais expostos e suscetíveis a condições de isolamento social que se manifestam em termos de ampliação de situações contingenciais, capazes de produzir inseguranças e sofrimentos, passíveis de serem diagnosticados e tratados como patologias e transtornos pelos dispositivos médicos.

Parece que estamos lidando com um novo estágio do mal-estar civilizatório, aquele em que a comunalidade dos laços sociais vai se desintegrando, na medida em que as diretrizes individualistas dominantes se exacerbam em função dos frenesis da produtividade e do consumo. O sofrimento (que pode ser designado por "ansiedade") seria um efeito adverso desta cultura do medo e dos riscos.

Exige-se que estejamos devidamente aparelhados pela tecnológica providência, para estarmos aptos por meio de métodos e técnicas como formas efetivas de prever e enfrentar os sortilégios desconhecidos reservados pelas veredas de nossos destinos. Nesse contexto, surgem propostas individualistas de gestão do estresse, de treinamento "resiliente" com vistas à superação das nossas supostas debilidades, sem referência explícita ao contexto socioeconômico e cultural.

A insana tarefa de lidar com as manifestações indesejáveis diante do atual estado das coisas, seja respondendo com "pânico", "ansiedade", "estresse”, "somatizações” e/ou "sofrimento difuso" constitui um sintoma resultante dos processos de tentar dar sentido e dar conta das incidências culturais provenientes da desmedida preocupação com o medo e suas vicissitudes. Portanto, ao se tratar da comunicação do risco, devemos cogitar acerca das matrizes produtoras desta poderosa concepção que surge com as grandes navegações ibéricas e as ameaças constituídas pelos rochedos e penhascos na busca de bens e terras colonizáveis.

A ideia de risco pode ser encarada atualmente como uma das várias formas alegóricas que colonizam as maneiras como as pessoas procuram, não sem muitas dificuldades, dar sentido a seu mal-estar. Baseado em Wilkinson 20, é possível afirmar não ser humanamente possível haver acordo final diante da quantidade e magnitude dos riscos que são apresentados pelos canais de comunicação de risco. Nem é viável cogitar que o atual grande aumento da sensibilidade aos riscos pode ser considerado como resposta "normal" e "racional" ao futuro que aguardamos.

Tanto o cálculo como a comunicação das probabilidades que representam os riscos ocorrem em consonância com a ampliação da capacidade de gestão tecnológica para controlar as aleatoriedades e complexidades do mundo. Esse empreendimento deve ser alcançado em função do conhecimento reunido em relação às regularidades estabelecidas dos eventos de interesse já ocorridos. Assim seria factível calcular os graus de incerteza com os quais se poderia, baseando-se nessa ideia de passado presentificado pelos dados pretéritos, planejar tecnocraticamente nosso futuro. 
Há que se levar em conta que as estimativas de risco resultam de determinantes técnicos e políticos diferentes sobre a "realidade" dos riscos como um efeito inevitável da tentativa de submeter a experiência de mal-estar a nossas categorias de entendimento racional/instrumental. E, também, sem que se explicitem os pressupostos de tais categorias. Law 22 assinala que há a esse respeito premissas não discutidas sobre a ideia de realidade externa como sendo, em geral: independente de nossas ações e, em especial, de nossas percepções; anterior ao supostamente preceder à nossa existência; definível, uma vez que seria constituída por um conjunto definido de formas e relações; singular, em função do fato de, mesmo podendo haver várias versões da realidade, o mundo seria comum a todos, o mesmo em qualquer lugar onde se esteja.

Enquanto os significados atribuídos à noção de risco foram ficando progressivamente mais controversos e, portanto, desnorteantes, sua dimensão paradoxal foi se manifestando cada vez mais. Por um lado, esse conceito é empregado de forma a sustentar as certezas da razão calculista para prever os acontecimentos futuros em termos de afirmações probabilísticas. Alternativamente, tem o potencial de elevar a incerteza que se manifesta diante das tentativas de se utilizar processos racionais empírico-lógicos nas tentativas de desvelar o futuro, sem atentar para as complexas intrincações deste empreendimento.

As distintas concepções acerca da relação risco/mal-estar/medo tendem a ser politicamente construídas de modo a nos induzir a chegar a uma posição favorável à atuação de peritos e especialistas. Também, levam-nos a aceitar uma suposta certificação quanto à solidez tanto em termos das respectivas confiabilidade e legitimação moral sustentadas por um implícito arcabouço ético validado por meio de dispositivos estatísticos, tal como foi formulada pelos expertos em comunicação de riscos anteriormente apresentados.

Não é despropositado cogitar que possa haver uma grande defasagem entre todas as perspectivas da relação entre a produção do medo, gestão dos riscos e a produção de serenidade, bem como a dilatação do mal-estar. As pessoas assumem e constroem saberes sobre perigos, ameaças e imponderabilidades em meio a seus desafios sociais, em suas circunstâncias específicas de levar suas existências. As práticas preemptivas de saúde, em termos de responsabilidade pessoal na vida cotidiana, representam cada vez mais aspectos fundamentais dos valores instrumentais e utilitaristas sustentados pelas sociedades contemporâneas marcadas pelo neoliberalismo. Sob esse panorama conflui a relação entre progresso sociotécnico, crescimento econômico e controle racional.

Cidadãos corretos podem exercer sua autonomia individual, sobretudo por meio de seu poder de consumo de mercadorias. Em geral, poderiam, em especial, garantir sua segurança em saúde por intermédio de práticas e tecnologias que visam à evitação dos riscos. Essa formulação securitária nos conduz a uma constatação que pode transitar entre a ironia e o cinismo: quanto mais se dedica a tal hiperprevenção em saúde, mais somos assombrados por insegurança e ansiedade, pelas quais pagamos seus preços, queiramos ou não.

Portanto, lidar com a comunicação que visa a controlar riscos para proteger e promover a saúde, implica habitar um território agonístico envolvendo disputas de poder, com inevitáveis ganhos e perdas. É preciso estar atento aos enunciados de proteção, promoção, prevenção e preempção em saúde, pois podem refletir ações concomitantes de vários vetores de diferentes origens e interesses, eventualmente estruturados de forma cínica. Mais do que propor modelos instrumentais de intervenção, é preciso captar e decifrar as enunciações comunicacionais em suas ambiguidades, como maneira de sustentar a reflexão crítica sobre as práticas que ainda pretendem buscar alternativas às formas precárias de se levar a vida na contemporaneidade.

Nessa linha de raciocínio, seguindo Safatle 23, é importante partir dos modos de "gestão social do medo" com sua conexão direta com a perspectiva dos riscos, também em seus processos comunicacionais, em função de sua produção e circulação como estratégia fundamental de submissão às normas. O medo seria o "afeto" político essencial, inseparável do entendimento do indivíduo contemporâneo, com seus interesses e limites a serem intensamente defendidos no interior do individualismo dominante. Consequência necessária da política utilitária liberal que define, implicitamente, o outro como uma espécie de "invasor potencial". Os preceitos supostos de liberdades individuais estão vinculados à gestão e produção social do medo.

É importante enfatizar que há um lugar para além da ideia de informação pletórica sobre os riscos que mais nos atordoam e nos levam a descaminhos. Mais do que nos orientam e permitem sustentar a 
possibilidade de que ainda nos cabe resistir aos agentes do mal-estar nosso de cada dia. É nesse cotidiano que a gestão dos riscos decerto tende a ocupar um papel obsedante e, ironicamente, impossível de dar conta do riscado.

Essa é a intenção deste texto ao tentar mostrar os paradoxos dos arautos neocomportamentalistas da comunicação cientificista do risco. É preciso que haja outras formas de vida, que não sejam constituídas por rituais preventivos e relatos individualistas. Os incursos de colonização do mundo da vida pelas práticas e falas desses arautos especialistas se dão na tessitura sub-reptícia de uma sinfonia trágica, de visões de mundo e padrões culturais inspirados à imagem das perspectivas preemptivas das ciências estatísticas e à medida da avidez dos mercados.

As nascentes de dissensões e ainda frágeis resistências, em antagonismo efêmero, correm por desertos e ao contorno de bordas que parecem intransponíveis. As cosmologias aqui descritas, assim como os pseudo-alarmes delas decorrentes, se dão em encenações midiáticas crescentemente familiares, expostas a indivíduos cada vez mais culturalmente precarizados. São mensagens encenadas a plateias diferentes daquelas presentes nas salas de TV familiares nas últimas décadas do século $\mathrm{XX}$. As retóricas preemptivas crescem nessa direção - pelo meio de acesso direto às subjetividades, dirigindo-se, sem intermediários, a indivíduos cada vez mais ávidos de comunicação transmissional que habitam as bolhas supostamente interativas, por meio de smartphones, tablets, notebooks. Tais mensagens proliferam como "mantras" na ausência de contradições ou condições de interlocução. São ampliadas pelo comovente desinteresse pelas dissensões em terrenos de escassez de nortes de referência, na miopia de perspectivas empobrecidas do "como" e do "por quê" da vida.

A sobrevalorização da saúde traz subjacente a suas alegorias os paradoxos danosos gerados pelas atuais facetas deste capitalismo duramente excludente, que produz, sim, alguns vencedores, mas muitos e muitos Severinos derrotados.

\section{Colaboradores}

L. D. Castiel propôs a concepção e desenvolveu a linha argumentativa do texto. P. R. VasconcellosSilva e D. R. Moraes colaboraram com a revisão crítica e a adequação do texto às normas do periódico. 


\section{Referências}

1. Business Dictionary. Risk communication. http://www.businessdictionary.com/defini tion/risk-communication.html (acessado em 29/Nov/2016).

2. Agência Nacional de Vigilância Sanitária. Controle de alimentos: aplicação dos princípios de análise de risco. In: XIX Congresso $\mathrm{Na}$ cional de Laticínios. http://www.anvisa.gov. br/alimentos/aulas/congresso_laticinios.ppt (acessado em 29/Nov/2016).

3. Sheppard B, Janoske M, Liu B. Understanding risk communication theory: a guide for emergency managers and communicators. Report to Human Factors/Behavioral Sciences Division, Science and Technology Directorate, U.S. Department of Homeland Security. https:// www.start.umd.edu/sites/default/files/files/ publications/UnderstandingRiskCommunica tionTheory.pdf (acessado em 27/Jan/2017).

4. Covello VT. Risk communication: an emerging area of health communication research. In: Deetz SA, editor. Communication yearbook 15. Newbury Park: Sage; 1992. p. 359-73.

5. Fischhoff B. Risk perception and communication unplugged: twenty years of process. Risk Anal 1995; 15:137-45.

6. Bennett P, Calman K, Curtis S, FischbacherSmith D. Understandig public responses to risk. In: Bennett P, Calman K, Curtis S, Fischbacher-Smith D, editors. Risk communication and public health. London: Oxford University Press; 2010. p. 3-22.

7. Rangel-S ML. Comunicação no controle de risco à saúde e segurança na sociedade contemporânea: uma abordagem interdisciplinar. Ciênc Saúde Coletiva 2007; 12:1375-85.

8. Porto MFS, Freitas CM. Análise de riscos tecnológicos ambientais: perspectivas para o campo da saúde do trabalhador. Cad Saúde Pública 1997; 13 Suppl 2:59-72.

9. Arden-Pope C, Ezzati M, Dockery DW. Fineparticulate air pollution and life expectancy in the United States. N Engl J Med 2009; 360:376-86.

10. Blastland M, Spiegelhalter DJ. The norm chronicles, stories and numbers about danger. London: Profile Books; 2013.
11. Spiegelhalter DJ. Using speed of ageing and "microlives" to communicate the effects of lifetime habits and environment. BMJ 2012; 345:e8223.

12. Spiegelhalter DJ, Pearson M, Short I. Visualizing uncertainty about the future. Science 2011; 333:1393-400.

13. Howard RA. Microrisks for medical decision analysis. Int J Technol Assess Health Care 1989; 5:357-70

14. Até Quando Você Quer Viver (Reality de Saúde) - Ep Ismael. http://gnt.globo.com/ programas/ate-quando-voce-quer-viver/episo dios/772.htm (acessado em 27/Jan/2017).

15. Castoriadis C. As encruzilhadas do labirinto V: feito e a ser feito. Rio de Janeiro: DP\&A; 1999.

16. Instituto Antônio Houaiss. Dicionário Houaiss da Língua Portuguesa. Rio de Janeiro: Editora Objetiva; 2000

17. Merriam-Webster Dictionary. Precarious. http://www.merriam-webster.com/diction ary/precarious (acessado em 27/Jan/2017).

18. Standing G. The precariat: the new dangerous class. London: Bloomsbury Academic; 2011.

19. Bauman Z, Donskis L. Cegueira moral: a perda da sensibilidade na modernidade líquida. Rio de Janeiro: Jorge Zahar Editor; 2014.

20. Wilkinson I. Anxiety in a risk society. London: Routledge; 2001.

21. Merklen D. Las dinámicas contemporaneas de individuación. In: Castel R, Kessler G, Merklen D, Murard N, organizadores. Individuación, precariedad, inseguridad. ¿Desinstitucionalización del presente? Buenos Aires: Paidós; 2013, p. 45-86.

22. Law J. After method: mess in social science research. London: Routledge; 2004.

23. Safatle V. O circuito dos afetos: corpos políticos, desamparo e o fim do indivíduo. Belo Horizonte: Editora Autêntica; 2016. 


\section{Abstract}

This essay problematizes the dominant approach to health risk communication. It thus consults and analyzes authors that present themselves as experts in risk communication and passages from mainstream audiovisual media broadcasts. While risk communication appears as an area of mediation between experts and the lay public, with the potential to generate technological innovation and potentially consumable merchandise, health risk communication occupies a biopolitical place that reinforces blaming individuals and individualizing risk avoidance proposals. The effacement of the contexts in which risk exposures occur feeds and is fed by the current neoliberal context. In addition to attempts at mediation that are often problematic, the rational and individual risk management perspective, no matter how fully equipped with innovative technologies, fails to ameliorate the contextual precariousness in which health risks are produced. Paradoxically, the belief in risk management (the dominant approach in health risk communication) ends up producing moralization, anxiety, and malaise.

Communication; Risk; Health

\section{Resumen}

Este ensayo problematiza el enfoque dominante de la comunicación de riesgos en salud. Para ello, accede y toma para su análisis contenido proveniente tanto de autores que se presentan como especialistas en el área de comunicación de riesgos, como de secuencias de medios audiovisuales de amplia difusión. Asimismo, parece que se configura un área de mediación entre expertos y profanos en la materia, potencial generadora de innovación tecnológica y de servicios pasibles de ser consumidos, donde la comunicación de riesgos en salud ocupa un lugar biopolitico de refuerzo de la culpabilización de los individuos y de propuestas individualizantes de evitación de riesgos. La desaparición de los contextos en los que se producen las exposiciones al riesgo alimenta y es alimentada por la coyuntura neoliberal en la que vivimos. Además de las tentativas de mediación, que son muchas veces problemáticas, la perspectiva de gestión racional e individual de los riesgos, por muchas tecnologías innovadoras que lleve aparejada, no minimiza la precariedad contextual en la que se produce la producción de los riesgos sanitarios. Paradójicamente, la creencia en la gestión de los riesgos, presente en el enfoque dominante de la comunicación de los riesgos en salud, acaba por producir moralización, ansiedad y malestar.

Comunicación; Riesgo; Salud
Recebido em 02/Fev/2017

Versão final reapresentada em 23/Mai/2017 Aprovado em 27/Jun/2017 